\title{
Synthetic agrochemicals: a necessary clarification about their use exposure and impact in crop protection
}

\author{
Patrice A. Marchand ${ }^{1}$ (D) \\ Received: 7 March 2019 / Accepted: 2 May 2019 / Published online: 15 May 2019 \\ (C) Springer-Verlag GmbH Germany, part of Springer Nature 2019
}

\begin{abstract}
Synthetic pesticides are largely decried. A common attitude against the synthetic agrochemicals is to avoid, criticise or ban these substances. Along with chemical pesticides to defend crops from bioagressors are microorganisms, semiochemical and natural substances used as plant protection products including biocontrol agents (BCAs) and crop protection products in organic production. Nevertheless, a natural substance status does not confer or imply safety, security or absence of residues (in the context of plant protection). Although in this paper we do not consider the toxicological perspective of highly toxic chemicals with adverse effects on humans and non-target organisms sprayed on crops, we have applied ourselves to working on the safe use of synthetic agrochemicals. Thus, along with biopesticides (either BCA or others) allowed in organic farming, we show that some synthetic chemical pesticides may be used in safe manner.
\end{abstract}

\section{Highlights}

- Synthetic agrochemicals are widely criticised.

- Some pesticide usages are not sprayed on crops.

- Some biocontrol agents are of synthetic origin.

Keywords Agrochemicals $\cdot$ Synthetic molecules $\cdot$ Biocontrol agents (BCAs) $\cdot$ Maximum residue limits (MRLs) $\cdot$ EU pesticide regulation

\section{Introduction}

Globally, there is a negative perception of synthetic agrochemicals (Coats 1994) compared to plant protection products of natural origin defined here as biocontrol. Biocontrol in its widest sense encompasses all the natural means of plant protection, including macro-organisms and biocontrol agents (BCAs), the latter have been covered by the pesticide regulation in Europe. In fact, BCAs or biorationals are increasing and promising due to their specificity, often with narrow mode of action and/or safe uses, but this is not always so. BCAs are natural substances (from mineral, plant, microbial and animal origin), microorganisms and semiochemicals used in plant

Responsible editor: Philippe Garrigues

Patrice A. Marchand

patrice.marchand@itab.asso.fr

1 Institut de l'agriculture et de l'alimentation biologiques (ITAB), 149 rue de Bercy, 75595, 12 Paris Cedex, France protection (Robin and Marchand 2019a). In contrast, synthetic pesticides are the subject of much concern (Stenersen 2004; Mitra et al. 2011) and are increasingly subject to criticisms and suspicions.

Agrochemical active substances, and especially chemical ones, are often the subject of controversial comments (Lamichhane et al. 2016; Oberemok et al. 2017). From a legal perspective, most of them are granted with maximum residue limits which must be respected, with the penalty that it will not be possible to sell them, if these limits are exceeded. Thus, checking for pesticides, contamination is monitored throughout the EU. Initially, pesticides are monitored in water resources (Water Framework Directive; EC 2000). Lately, although there is still no soil directive in EU, pesticide residues in soil will be monitored as well as in French soils as part of the phytopharmacovigilance national plan placed under the authority of ANSES (MAAF 2016). Despite this, the presence of even legal residues in agricultural products is also controversial. In reaction, some private labels claim even lower residues than the legal minimums, sometimes below the limit of quantification (LOQ) (Charon et al. 2019). Any molecule is a 
chemical, but a chemical is a nasty molecule in many people's thoughts, obviously forgetting that some, like water, are indeed and undoubtedly dihydrogen oxide molecule. Again, natural compounds are also chemical molecules and sometimes are undoubtedly dangerous (Dembitsky and Rezanka 2003).

\section{EU pesticide evaluation}

The agrochemical active substance EU evaluation process (Robin and Marchand 2019) mainly considers the 'matter' as one entity and, only with difficulty, goes beyond single molecules or a small sum of single molecules. As an example, although only part of the cell wall of the microorganism Saccharomyces cerevisiae which constitutes the active substance 'cerevisane', it was barely considered as a living organism during initial evaluation by European Food Safety Authority (EFSA), during the application for its use as a plant strengthener under plant protection regulations. Again, recent considerations for the same active substance in organic production involved the same symptomatic approach; it was assimilated as a microorganism then treated as a natural substance from microbial origin (EGTOP 2019). Regulations require that active substances are attributed to one category and only one.

However, agrochemical uses or usages may be a more appropriate means of their classification. Clearly, chemicals contained and constrained in varied traps, well managed with no crop contaminations and not dispersed into the wider environment should be considered useful and without risk since danger is not coupled with any exposure; thus, the wellknown and admitted formula $R=D \times E$ (risk $=$ danger $\times$ exposure) gives rise to a lack of $R$ even without knowing the value of $D$ during an assessment (Aven 2012).

In field situations, the contrast is even starker, as contamination by agrochemical residues is the most important parameter to take into consideration. Thus, any option to reduce or suppress residues in the crop production and environment should be used and encouraged.

\section{Material and methods}

\section{Materials and data}

Previous work on EU-approved active substances allowed us (Robin and Marchand 2019) to collect data in order to establish and maintain a global table of information on all EU substances since 2011, their approval, non-approval, renewal, non-renewal and termination regarding EU Pesticides Regulation (EC) No. 1107/2009 (EC 2009a).

\section{EU Pesticides database}

The EU Pesticides database (DGSanté 2019) is an updated online database that records all active substances dependent on EU Pesticides regulations, whether approved or not, which are listed in the Implementing Regulation (EU) No. 540/2011 (EU 2011).

\section{European regulations}

Regulation (EC) No. 396/2005 allocates the maximum residue limits (MRLs) of all pesticides. A consolidated version of this regulation with all modifications and updates may be found via the EUR-Lex website (EC 2005). It may also be useful to check a consolidated version of the Implementing Regulation (EU) No. 540/2011 (EU 2011) for all changes in the approval/renewal/withdrawal process. The method to provide a list of active substances with an MRL on Annex IV of Regulation (EC) No. 396/2005 is already described (Charon et al. 2019).

\section{Methodology: database search}

The EU Pesticides database may be interrogated in diverse ways, as by substance type (DGSanté 2019) for basic and low-risk substances. MRLs for all active substances in corresponding crops are detailed, but no search can be performed with MRLs or location in the corresponding annexes of Regulation (EC) No. 396/2005; therefore, a manual search is needed. Thus, up to now, no automatic search may be completed in the EU Pesticides database with the advance search process. However, full MRLs in XML format may be downloaded from the EU website (Robin and Marchand 2019a; Charon et al. 2019).

\section{Pesticide database analyses}

The commission-implementing regulations amending Regulation (EU) No. 540/2011 were used to trace the history of agrochemical substances from 2011 to the present and took into account all approvals, approval extensions and renewals of substances, together with their approved period. The EU Pesticides database was used to assign the function (i.e. insecticide) of each biocontrol substance. These functions were then analysed (EU 2019a).

\section{MRL analyses}

MRLs for all active substances in corresponding crops are detailed, but no search can be performed with MRL or location in the corresponding annexes of Regulation (EC) No. 396/2005; therefore, a manual search is required. Thus, up until now, no automatic search could be undertaken on the 
EU Pesticides database with the advance search process. However, full MRLs in XML format may be downloaded from the website (EU 2019b).

\section{Results}

Synthetic agrochemicals still form the larger part of a list of the total EU active substances ( 297 vs 187 ) compared to biocontrol substances, but the situation is complex and their uses are diverse. Most relevant substances for this opinion paper were identified during previous work (Robin and Marchand 2019a; Charon et al. 2019).

Some agrochemicals are considered as synthetic because of their non-natural origin and are described as exogenous pesticides, whereas some are chemically equivalent to natural substances. Those may be called biomimetic compounds, in particular, for those that are chemically synthesised to produce naturally active compound equivalents, used as biopesticide or BCAs for the purposes of biocontrol. The reasons why a synthetic equivalent is used are mainly due to cost, either of production (extraction or purification) or of the raw vegetal material compared to other uses (i.e. perfumes). This applies mainly to small, flat or non-chiral molecules easily manufactured by synthetic chemistry from common starting blocks. Naturally, this is not the case for complex chiral molecules such as some pheromones (Corey et al. 1968).

Another BCA category may be of concern when evoking comparisons to synthetic processes, natural substances (NSs) and from those natural substances of mineral origin (NSM) (Robin and Marchand 2019). Again, quite a few of mineral origin, but equivalent to natural molecules, are produced synthetically: some copper compounds, bicarbonates, etc. Similarly, some natural substances of plant origin (NSV) are also commonly used in the synthetic form, such as auxins (e.g. indolebutyric acid (IBA)). This manufactured or chemical process does not inhibit them from being used in organic production.

Analysis of these databases shows diverse situations (mode of action, function) where synthetic agrochemicals are not sprayed on crops, or when no contact with crop productions occurs. Thus, controversial adverse effects blamed by civil society should not be applied to compounds with this mode of action or function. Corresponding functions may include repellent, attractant, sexual confusion and insecticide toward insects. The concept being suggested here is to propose consideration and guidance processes to discriminate substances based on their mode of action and operational use conditions, instead of their intrinsic chemical origin. However, the effort usually performed for naturally occurring substance to propose structural modification giving rise to synthetic parallel substances is to exhibit a better efficiency. This fate or goal, noticeable on pyrethrums and $\beta$-triketones, induces generally lower field rate (e.g. down to $2.5 \mathrm{~g} / \mathrm{ha}$ for deltamethrin in some usages). However, modified generated molecules usually exhibit lower degradation rates, higher non-intentional impacts on non-target species or higher selection pressure(s), although this is not the exclusive property of synthetic molecules.

\section{Pesticides not sprayed on crop situation}

\section{Biocontrol agents: relevant categories}

From all pesticides, BCAs are the most interesting products (Robin and Marchand 2019) associated with low toxicity and concern, but among BCAs, semiochemicals (SCs) are one category which does not come into contact with the crops produced. Thus, this SC category comprising attractant (AT), repellent (RE) and confusing substances is divided in two subcategories: pheromones (SCP) and allelochemical substances (SCA) and which could be from synthetic origin, but without any concern about residues. In fact, many of them are synthetically equivalent and manufactured in order to reduce production costs. This category represents actually 40/187 of the BCA substance in EU regulations.

\section{Chemicals}

Some chemical insecticides are also used in a non-contact manner. This strategy is called attract-and-kill (Kroschel and Zegarra 2010; Gregg et al. 2018). They are positioned in traps, coupled with chemical, bright lights, odorous attractants or coloured attractants. Up to now, deltamethrin and lambdacyhalothrin are commonly used in traps in Europe as a biocide to kill attracted insects. Both are considered as coupled with biocontrol and even allowed in organic production for this specific use. But, considering the problematic toxicological concern of both compounds and the necessity of substitution in their spraying mode of use, they may disappear in a short time.

\section{The situation of pesticides sprayed on crops}

Some others, including synthetic chemical pesticides, are sprayed directly onto crops and seeds or used for postharvest treatment but are granted with no MRL as they give rise to no residue of concern. These substances are registered in Annex IV of Regulation (EC) No. 396/2005, and their search pathway and complete list were described previously (Charon et al. 2019). Those are low molecular weight compounds (i.e. geraniol), are labile (i.e. hydrogen peroxide) and/ or are similar to natural molecule substances (i.e. carvone, acetic acid vs vinegar). This group represents actually around 120 substances from all types in EU; regular active and basic substances (Marchand 2015, 2016) and low-risk lists include chemical molecules (Marchand 2017). 
The total number of substances taken into account for this point of view is finally from 120 to 160 (some substances may be considered by both categories); thus, $30 \%$ to $40 \%$ from the total 387 active substances were approved in EU.

\section{Discussion}

National or EU wide policy restrictions and constrains on pesticides, together with approval processes, already take care of this situation (EC 2009b) through National Action Plans (DGSanté 2018), granting those substances and corresponding plant protection products (PPPs) for either evaluation or pollution taxes for uses in fields with less fees. Substances of little or no concern are highlighted, however; chemical pesticides are always stigmatised in official public speeches and information to consumers. Indeed, approved low-risk and basic substances (EC 2009a) comprise predominantly biocontrol agents (EC 2009a); thus, only few chemicals are approved in these categories, but still some are approved (i.e. ferric phosphate, hydrogen peroxide).

\section{Policy implications}

Recent incentives through financial motivations at different stages and recent modifications of low-risk criteria may open the opportunity of lower molecular weight chemicals in this category (EP 2017; EU 2017). In fact, similar opportunities for light chemicals are also opened by article 25 and Annex I of the biocide regulation 528/2012 (EU 2012). Indeed, regarding plant protection, few chemicals are already listed in the corresponding issue of this commitment (EU 2018). However, the ongoing restricted list of encouraged plant protection products at national level (ECOPHYTO 2018) is only targeted to support biocontrol agents without any other consideration. As an example, the French law for the agroecology transition (Loi No. 2014-1170 2014) can be cited here as well because it pushes in front biocontrol as a serious option to consider to replace agrochemicals. Lately, a favourable vote at the PAFF committee as regards to the establishment of harmonised risk indicators for Article 53 (emergency derogations) at Directive (EC) No. 2009/128 will positively affect the choice for substances with less concern like BCA.

Later evolution by incitement of integrated pest management (IPM) (EU 2019c) and refinement of pesticide authorisation procedure (EU 2019d) may create a better framework for pesticide uses including the actual toxicological status of the substances and their residues, and not whether they belong to a particular subcategory at regulatory or plant protection concept level.

\section{Conclusions}

As far as this work makes reference to the interest of chemical pesticide substances in some specific uses, it is not a recommendation for synthetic pesticides in all configurations (GAP) of uses.

But, not all chemically synthetic pesticides should be considered as intrinsic pollution and contamination of crops and crop production when used as plant protection products. Generally, negatively considered by civil society should be attenuated by the integration of the 'use condition' factor when considering chemical pesticides. This information and education of the public must be performed together with the transfer of knowledge, in conjunction with the recommendations of the Directive No. 2009/128/EC and the National Action Plans in order to avoid further and continuous misunderstanding on the part of civil society of pesticide and pesticide use in general and synthetic agrochemicals in particular. In this goal, communication about biocontrol and BCAs should underline these aspects together with regular BCApromoting actions.

\section{Perspective}

Knowledge of strategies to avoid chemical crop contaminations through specific usages, mode of action or containment manner may be conducive to the better use of synthetic agrochemicals. Therefore, reduction possible to complete ban, observed in EU since the peak substance (Robin and Marchand 2019), of these types of plant protection products may not be the only way to reduce chemical pesticide contaminations.

Acknowledgements The author would like to thank Dr. Trevor M. Fenning of Forest Research (UK) for providing the helpful advice on the editing and writing of the manuscript.

Financial support This study was supported by the French Ministry of Ecology by Agence Française pour la Biodiversité (XP-BC 2017-2019).

\section{References}

Aven T (2012) The risk concept-historical and recent development trends. Reliab Eng Syst Saf 99:33-44

Charon M, Robin D, Marchand PA (2019) The major interest for crop protection of agrochemical substances without maximum residue limit (MRL). Biotechnol Agron Soc Environ 23(1):22-29. https:// doi.org/10.25518/1780-4507.17666

Coats JR (1994) Risks from natural versus synthetic insecticides. Annu Rev Entomol 39:489-515. https://doi.org/10.1146/annurev.en.39. 010194.002421

Corey EJ, Katzenellenbogen JA, Gilman NW, Roman SA, Erickson BW (1968) Stereospecific total synthesis of the dl-C18 Cecropia juvenile hormone. J Am Chem Soc 90(20):5618-5620. https://doi.org/10. 1021/ja01022a060 
Dembitsky VM, Rezanka T (2003) Natural occurrence of arseno compounds in plants, lichens, fungi, algal species, and microorganisms. Plant Sci 165(6): 1177-1192

DGSanté (2018) EU National Action Plans https://ec.europa.eu/food/ plant/pesticides/sustainable use pesticides/nap en [Accessed: January 9, 2019]

DGSanté (2019) EU Pesticide database. Available on: http://ec.europa.eu/ food/plant/pesticides/eu-pesticides-database/public/?event $=$ activesubstance. selection\&language $=\mathrm{EN}$ [Accessed: January 9, 2019].

EC (2000) Directive (EC) No. 2000/60 of the European Parliament and of the Council of 23 October 2000 establishing a framework for community action in the field of water policy. OJ L 327 of 22.12.2000, pp. 1-73. https://eur-lex.europa.eu/legal-content/EN/TXT/?uri= CELEX:32000L0060 [Accessed: May 9, 2019]

EC (2005) Regulation (EC) No. 396/2005 on maximum residue levels of pesticides in or on food and feed of plant and animal origin and amending Council Directive 91/414/EEC. OJ L 70 of 16.3.2005, pp. 1-16. https://eur-lex.europa.eu/legal-content/EN/ALL/?uri= CELEX:32005R0396 [Accessed: May 9, 2019]

EC (2009a). Regulation (EC) No. 1107/2009 concerning the placing of plant protection products on the market and repealing Council Directives 79/117/EEC and 91/414/EEC, OJ L 309 of 24.11.2009, pp. 1-50. https://eur-lex.europa.eu/legal-content/EN/TXT/?uri= CELEX:32009R1107 [Accessed: May 9, 2019]

EC (2009b). Directive (EC) 2009/128 of the European Parliament and of the Council of 21 October 2009 establishing a framework for Community action to achieve the sustainable use of pesticides, OJ L 309 of 24.11.2009, pp. 71-86. https://eur-lex.europa.eu/legal-content/ EN/TXT/?uri=CELEX:32009L0128 [Accessed: May 9, 2019]

ECOPHYTO (2018). Liste des produits de biocontrôle http://www. ecophytopic.fr/tr/r\%C3\%A9glementation/mise-sur-le-march\%C3\% A9-des-produits/liste-des-produits-de-biocontr\%C3\%B4le-note-deservice [Accessed: January 9, 2019]

EGTOP (2019) Plant Protection IV, draft/final report, Directorate-General for Agriculture and Rural Development, in print. https:/ec.europa. eu/info/sites/info/files/food-farming-fisheries/farming/documents/ final-report-egtop-plant-protection-iv_en.pdf [Accessed: May 9, 2019]

EP (2017) European Parliament resolution of 15 February 2017 on lowrisk pesticides of biological origin (2016/2903(RSP)). OJ C 252 of 18.7.2018, pp. 184-188. http://www.europarl.europa.eu/doceo/ document/TA-8-2017-0042_EN.pdf [Accessed: May 9, 2019]

EU (2011) Commission implementing Regulation No. 540/2011 implementing Regulation (EC) No. 1107/2009 of the European Parliament and of the Council as regards the list of approved active substances, OJ L 153 of 11.6.2011, pp. 1-186. https://eur-lex. europa.eu/legal-content/EN/TXT/?uri=CELEX:32011R0540 [Accessed: May 9, 2019]

EU (2012) Regulation (EU) No. 528/2012 of the European Parliament and of the Council of 22 May 2012 concerning the making available on the market and use of biocidal products, OJ L 167 of 27.6.2012, pp. 1-123. https://eur-lex.europa.eu/legal-content/EN/TXT/?uri= CELEX:32012R0528\&qid=1557426837176 [Accessed: May 9, 2019]

EU (2017) Commission Regulation (EU) 2017/1432 amending Regulation (EC) No. 1107/2009 of the European Parliament and the Council concerning the placing of plant protection products on the market as regards the criteria for the approval of low-risk active substances. OJ L 205 of 8.8.2017, pp. 59-62. https://eur-lex.europa. eu/legal-content/EN/TXT/?qid=1557426907371\&uri=CELEX: 32017R1432 [Accessed: May 9, 2019]

EU (2018) Commission notice concerning a list of potentially low-risk active substances approved for use in plant protection. C/2018/4828.
OJ C 265 of 27.7.2018, pp. 8-11. https://eur-lex.europa.eu/legalcontent/EN/TXT/?uri=CELEX:52018XC0727(01)\&qid= 1557426963787 [Accessed: May 9, 2019]

EU (2019a). EU Pesticides database (2018). Available: http://ec.europa. $\mathrm{eu} /$ food $/$ plant/pesticides/eu-pesticides-database/public/?event= activesubstance.selection\&language $=\mathrm{EN}$, [Accessed: 7 April 2019].

EU (2019c). Integrated pest management (IPM). Available on: https://ec. europa.eu/food/plant/pesticides/sustainable use pesticides/ipm en [Accessed: January 9, 2019].

EU (2019d). PEST, EU authorisation procedure for pesticides. Available on: http://www.europarl.europa.eu/committees/en/pest/home.html [Accessed: January 9, 2019].

Gregg PC, Del Socorro AP, Landolt PJ (2018) Advances in attract-andkill for agricultural pests: beyond pheromones. Annu Rev Entomol 63:453-470. https://doi.org/10.1146/annurev-ento-031616-035040

Kroschel J, Zegarra O (2010) Attract-and-kill: a new strategy for the management of the potato tuber moths Phthorimaea operculella (Zeller) and Symmetrischema tangolias (Gyen) in potato: laboratory experiments towards optimising pheromone and insecticide concentration. Pest Manag Sci 66(5):490-496. https://doi.org/10.1002/ps. 1898

Lamichhane JR, Dachbrodt-Saaydeh S, Kudsk P, Messéan A (2016) Toward a reduced reliance on conventional pesticides in European agriculture. Plant Dis 100(1):10-24

MAAF (2016) Décret no 2016-1595 du 24 novembre 2016 relatif à la phytopharmacovigilance et modifiant diverses autres dispositions du code rural et de la pêche maritime relatives à la protection des végétaux. NOR: AGRG1517899D, Text 49 over 130, JORF of 26.11.2016, pp. 1-4. https://www.legifrance.gouv.fr/eli/decret/ 2016/11/24/AGRG1517899D/jo/texte [Accessed: May 9, 2019]

Marchand PA (2015) Basic substances: an approval opportunity for low concern natural products under EU pesticide regulation. Pest Manag Sci 71(9):1197-1200. https://doi.org/10.1002/ps.3997

Marchand PA (2016) Basic substances under EC 1107/2009 phytochemical regulation: experience with non-biocide and food products as biorationals. Journal of Plant Protection Research 56(3):312-318. https://doi.org/10.1515/jppr-2016-0041

Marchand PA (2017) Basic and low risk substances under EU pesticide regulation: a new choice for biorationals portfolio of small and medium-sized enterprises. Journal of Plant Protection Research 57(4):433-440. https://doi.org/10.1515/jppr-2017-005616

Mitra A, Chatterjee C, Mandal FB (2011) Synthetic chemical pesticides and their effects on birds. Res J Environ Toxicol 5(2):81-96

Oberemok VV, Laikova VK, Zaitsev AS, Temirova ZZ, Gal'chinsky NV, Nyadar PM, Shumskykh MN, Zubarev IV (2017) The need for the application of modern chemical insecticides and environmental consequences of their use: a mini review. J Plant Prot Res 57(4):427432

Robin DC, Marchand PA (2019a) Biocontrol active substances: evolution since the entry in vigour of Reg. 1107/2009. Pest Manag Sci 75(4): 950-959. https://doi.org/10.1002/ps.5199

Robin DC, Marchand PA (2019) Evolution of Regulation (EU) No. 540/ 2011 since its entry into force. J Reg Sci 7:1.7

Stenersen J (2004) Chemical pesticides mode of action and toxicology. CRC, Boca Raton. https://doi.org/10.1201/9780203646830

Publisher's note Springer Nature remains neutral with regard to jurisdictional claims in published maps and institutional affiliations. 